\title{
Pivoting for a Pandemic
}

\author{
Tania Mysak
}

$I^{\prime}$ t was March 11. Organizational leadership had quickly gathered to make a critical decision with incomplete information, a deadline fast approaching, and in the context of shifting sands. The World Health Organization had just declared COVID-19 to be a global pandemic. On one hand, it was merely an acknowledgement of what was already known — a novel virus impacting multiple continents. On the other hand, it changed everything, setting in motion changes that would affect our work environments and personal lives in ways we did not fully comprehend.

The meeting in question was about the Canadian Society of Hospital Pharmacists' (CSHP's) Banff Seminar. We were huddled around a speaker in a small office (before physical distancing became the norm), conferring with colleagues and reviewing the options. The conference was scheduled to start within days, and Jody Ciufo, CSHP's Chief Executive Officer, had travelled to attend her first Banff Seminar in an atmosphere of eager anticipation. But storm clouds were gathering. The planning committee had been fielding calls for over a week from concerned speakers, sponsors, and participants. Given what we knew even at that point, could we continue with the conference? Could we afford the costs of cancellation? Could we afford the reputational risk of an outbreak among healthcare workers if we proceeded? In the end, we pulled the plug on a beloved connection point for members.

Why am I sharing this story with you? It's a simple illustration of how quickly CSHP had to pivot and adapt to a rapidly changing environment. Just as our personal lives and workplaces have been uprooted with change and chaos and a "new normal", so has CSHP life. The work and plans of the spring, summer, and possibly even the fall, have been refocused and reprioritized. Conferences were cancelled amid uncertainty as to when things would return to "normal". We shifted the focus of education to COVID-19 related webinars-all enthusiastically received. We regrouped and recalibrated to ensure we were at the right tables to advocate for critical drugs and prevent devastating shortages. Our Pharmacy Specialty Networks and COVID-19 website have become bustling hubs of knowledge gathering and sharing. We embraced virtual meetings

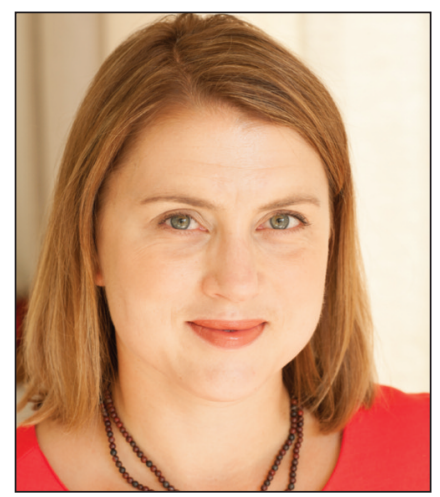
and connections. While there are still challenges ahead, many changes have been positive and allow us to explore new ways to meet member needs and advance our practices. Supporting CSHP members and their patients through COVID-19 is the job-overwhelming and gratifying all at the same time.

By the time you read this, we should be past the first peak of what is anticipated to be a series of waves to hit our healthcare system. Just as the experience has awakened society to the critical need for a strong public health system, I hope that it has also awakened our pharmacy community to the critical need for a strong professional society. I hope you have seen CSHP demonstrate the value we bring to pharmacy practice and to professional connections. Finally, I really hope you have shared that value with non-members and encouraged them to join and allow us to continue our critical work.

Tania Mysak, BSP, PharmD, is President and Vision Liaison for the Canadian Society of Hospital Pharmacists. 